This is an author produced version of a paper published in Nature.

This paper has been peer-reviewed and is proof-corrected, but does not include the journal pagination.

Citation for the published paper:

Cardinale, B. J.; Duffy, E.; Gonzalez, A.; Hooper, D.U.; Perrings, C.;

Venail, P.; Narwani, A.; Mace, G.M.; Tilman, D.; Wardle, D.A.; Kinzig, A.P.; Daily, G.C.; Loreau, M.; Grace, J.B.; Larigauderie, A.; Srivastava, D. and Naeem, S. (2012) Biodiversity loss and its impact on humanity. Nature. Volume: 486, Number: 7401, pp 59-67. http://dx.doi.org/doi:10.1038/nature11148.

Access to the published version may require journal subscription. Published with permission from: Macmillan Publishers Limited, Nature Publishing Group.

Epsilon Open Archive http://epsilon.slu.se 


\section{Biodiversity loss and its impact on humanity}

Bradley J. Cardinale ${ }^{1}$, J. Emmett Duffy ${ }^{2}$, Andrew Gonzalez ${ }^{3}$, David U. Hooper ${ }^{4}$, Charles Perrings ${ }^{5}$, Patrick Venail ${ }^{1}$, Anita Narwani ${ }^{1}$, Georgina M. Mace ${ }^{6}$, David Tilman ${ }^{7}$, David A. Wardle ${ }^{8}$, Ann P. Kinzig ${ }^{5}$, Gretchen C. Daily ${ }^{9}$, Michel Loreau ${ }^{10}$, James B. Grace ${ }^{11}$, Anne Larigauderie ${ }^{12}$, Diane Srivastava ${ }^{13}$, and Shahid Naeem ${ }^{14}$

${ }^{1}$ School of Natural Resources and Environment, University of Michigan, Ann Arbor, MI, U.S.A.

${ }^{2}$ Virginia Institute of Marine Science, The College of William and Mary, Gloucester Point, VA, U.S.A.

${ }^{3}$ McGill University, Department of Biology, Montreal, Quebec, Canada

${ }^{4}$ Western Washington University, Department of Biology, Bellingham, WA, U.S.A.

${ }^{5}$ School of Life Sciences, Arizona State University, Tempe, AZ, U.S.A.

${ }^{6}$ Centre for Population Biology, Imperial College London, Silwood Park, UK

${ }^{7}$ Department of Ecology, Evolution \& Behavior, University of Minnesota, Saint Paul, MN, U.S.A.

${ }^{8}$ Deptartment of Forest Ecology and Management, Swedish University of Agricultural Sciences, Umeå, Sweden

${ }^{9}$ Department of Biology and Woods Institute, Stanford University, Stanford, CA, U.S.A.

${ }^{10}$ Experimental Ecology Station, Centre National de la Recherche Scientifique, Moulis, France

${ }^{11}$ U.S. Geological Survey, National Wetlands Research Center, Lafayette, LA, U.S.A.

${ }^{12}$ Museum National d'Histoire Naturelle, Rue Cuvier, France

${ }^{13}$ Department of Zoology, University of British Columbia, Vancouver, BC, Canada

${ }^{14}$ Department of Ecology, Evolution, and Environmental Biology, Columbia University, New York, NY, U.S.A.

The most unique feature of Earth is the existence of life, and the most extraordinary feature of life is its diversity. Approximately 9 million types of plants, animals, protists and fungi inhabit the earth. So, too, do 7 billion people. Two decades ago, at the first Earth Summit, the vast majority of the world's nations declared that human actions were dismantling Earth's ecosystems, eliminating genes, species, and biological traits at an alarming rate. This observation led to a daunting question: How will loss of biological diversity alter the functioning of ecosystems and their ability to provide society with the goods and services needed to prosper?

In the last 20 years, we have made remarkable progress towards answering this question. Soon after the 1992 Earth Summit in Rio de Janeiro, interest in understanding how biodiversity loss might impact the dynamics and functioning of ecosystems, and the supply of goods and services grew dramatically. Major international research initiatives formed. Hundreds of experiments were performed in ecosystems all over the globe. New ecological theories were developed and tested against experimental results.

Here we review two decades of research that has examined how biodiversity loss influences ecosystem functions, and the impacts this can have on the goods and services ecosystems provide (Box 1). We begin with a brief historical introduction. We then summarize the major results from research that has provided increasingly rigorous answers to the question of how and why Earth's biological diversity influences the functioning of ecosystems. Following this, we consider the closely related issue of how biodiversity provides specific ecosystem services of value to humanity. We close by considering how the 
next generation of biodiversity science can reduce our uncertainties and better serve policy and management initiatives.

\section{A Brief History}

During the 1980 's, concern about the rate at which species were being lost from ecosystems led to research showing that organisms can influence the physical formation of habitats (ecosystem engineering ${ }^{1}$ ), fluxes of elements in biogeochemical cycles (e.g., ecological stoichiometry ${ }^{2}$ ), and the productivity of ecosystems (e.g., via trophic cascades and keystone species ${ }^{3}$ ). Such research suggested that loss of certain life forms could substantially alter the structure and functioning of whole ecosystems.

By the 1990s, several international initiatives were focused on the more specific question of how the diversity of life forms impacts ecosystems. The Scientific Committee on Problems of the Environment (SCOPE) produced an influential book reviewing the state of knowledge on biodiversity and ecosystem functioning (BEF) ${ }^{4}$. The United Nations Environmental Program commissioned the Global Biodiversity Assessment to evaluate the state of knowledge on biodiversity, including its role in ecosystem and landscape processes ${ }^{5}$. Building on early studies of the effects of biodiversity on ecosystem processes, DIVERSITAS, the international program dedicated to biodiversity science, produced a global research agenda ${ }^{6}$.

By the mid-1990's, seminal BEF studies had manipulated the species richness of plants in laboratory and field experiments and suggested that ecosystem functions, like biomass production and nutrient cycling, respond strongly to changes in biological diversity ${ }^{7-10}$. Interpretation of these studies was initially controversial, and by the late 1990's, BEF researchers were embroiled in a debate over the validity of experimental designs, the mechanisms responsible for diversity effects, and the relevance of results to non-experimental systems ${ }^{11}$. This controversy helped spawn a decade of research that, by 2009, generated several hundred papers reporting results of $>600$ experiments that manipulated more than 500 types of organisms in freshwater, marine, and terrestrial ecosystems ${ }^{12}$.

As the field of BEF developed, a related body of research began to form an agenda for biodiversity and ecosystem services (BES) research built on the idea that ecosystems provide essential benefits to humanity $^{13,14}$. While BES did not evolve separately from BEF, it took a distinctly different direction. The main focus of BES was on large scale patterns across landscapes more relevant to economic or cultural evaluation. For many BES applications, biodiversity was considered an ecosystem service in-and-of itself ${ }^{15}$. When biodiversity was viewed as an underlying factor driving ecosystem services, the term was often used loosely to mean the presence/absence of entire habitats or groups of organisms (e.g., impact of mangrove forests on flood protection, or of all native pollinators on pollination).

The 2005 Millennium Ecosystem Assessment ${ }^{16}$ appraised for the first time the condition and trends in the world's ecosystems and the services they provide, and highlighted two distinct foci of BEF and BES research. Research on BEF had developed a large body of experiments and mathematical theory describing how genetic, species, and functional diversity of organisms control basic ecological processes (functions) in ecosystems (Box 1). Studies on BES were, by contrast, mostly correlative, conducted at the landscape scale often focusing on how major habitat modifications influenced 'provisioning' and 'regulating' services of ecosystems. 
The 20th anniversary of the 1992 Earth Summit is an opportune time to review what has been learned from both fields, and to continue their synthesis towards a data-driven consensus. In the sections that follow, we summarize how biological variation per se acts as an independent variable to affect the functions and services of ecosystems.

\section{Years of Research on Biodiversity on Ecosystem Functioning (BEF)} In addition to the proliferation of experiments $(>600 \text { since } 1990)^{12}$, BEF research has developed a substantial body of mathematical theory ${ }^{17-19}$, and expanded its scope to include global patterns in natural ecosystems ${ }^{20-22}$. More than half of all work has been published since the last consensus paper in $2005^{23}$, and since that time, several milestones have been crossed: (1) the field has coalesced around a series of key findings and themes that have been fostered by the publication of thirteen quantitative data syntheses ${ }^{12,24-35},(2)$ many of the early scientific debates have subsided as data have amassed to resolve key controversies, and (3) a new consensus is emerging on the field's unanswered questions and how to address them. These milestones provide a unique opportunity to re-evaluate earlier conclusions and to identify emerging trends.

\section{Six consensus statements}

We conclude that the balance of evidence that has accrued over the last two decades justifies the following statements about how biodiversity loss impacts the functioning of ecosystems:

\section{There is now unequivocal evidence that biodiversity loss reduces the efficiency by which ecological communities capture biologically essential resources, produce biomass, decompose and recycle biologically essential nutrients}

Meta-analyses published since 2005 have shown that, as a general rule, reductions in the number of genes, species, and functional groups of organisms reduce the efficiency by which whole communities capture biologically essential resources (nutrients, water, light, prey), and convert those resources into biomass $^{12,24-28,30-35}$ (Fig. 1). Recent meta-analyses further suggest that plant litter diversity enhances decomposition and recycling of elements after organisms die ${ }^{12}$, though effects tend to be weaker than for other processes. Biodiversity effects appear remarkably consistent across different groups of organisms, among trophic levels, and across the various ecosystems that have been studied ${ }^{12,24,25,31}$. This consistency suggests there are general underlying principles that dictate how the organization of communities influences the functioning of ecosystems. There are exceptions to this statement for some ecosystems and processes ${ }^{12,32,36}$, and these offer opportunities to explore the boundaries that constrain biodiversity effects.

\section{There is mounting evidence that biodiversity increases the stability of ecosystem functions through time}

Numerous forms of 'stability' have been described, and there is no theoretical reason to believe that biodiversity should enhance all forms of stability ${ }^{37}$. But theory and data both support greater temporal stability of a community property like total biomass at higher levels of diversity. Five syntheses have summarized how diversity impacts variation of ecosystem functions through time ${ }^{38-42}$, and these have shown that total resource capture and biomass production are generally more stable in more diverse communities. The mechanisms by which diversity confers stability include overyielding, statistical averaging, and compensatory dynamics. Overyielding enhances stability when mean biomass production increases with diversity more rapidly than its standard deviation. Statistical averaging occurs when random variation in the population abundances of different species reduces the variability of aggregate ecosystem variables ${ }^{43}$. Compensatory dynamics are driven by competitive interactions and/or 
differential responses to environmental fluctuations among different life forms, both of which lead to asynchrony in their environmental responses ${ }^{18,44}$. We have yet to quantify the relative importance of these mechanisms and the conditions under which they operate.

The impact of biodiversity on any single ecosystem process is non-linear and saturating, such that change accelerates as biodiversity loss increases

The form of BEF relationships in most experimental studies suggests that initial losses of biodiversity in diverse ecosystems have relatively small impacts on ecosystem functions, but increasing losses lead to accelerating rates of change ${ }^{12,25,31}$ (Fig. 1). We do not yet have quantitative estimates of the level of biodiversity at which change in ecosystem functions become significant for different processes or ecosystems, and this is an active area of research ${ }^{12,31}$. While our statement is an empirical generality, some researchers question whether saturating curves are an artifact of overly simplified experiments ${ }^{45}$. Saturation could be imposed by the spatial homogeneity, short time-scales, or limited species pools of experiments that minimize opportunities for expression of niche differences. In support of this hypothesis, select case studies suggest that as experiments run longer, saturating curves become more monotonically increasing ${ }^{46}$. In addition, biodiversity-ecosystem function relationships in natural ecosystems sometimes differ from saturating curves $^{22}$, and future research needs to assess when and why these differences occur.

20 Diverse communities are more productive because (a) they contain key species that have a large influence on productivity, and (b) differences in functional traits among organisms increase total resource capture

Much of the historical controversy in BEF research involved the extent to which diversity effects are driven by single, highly productive species versus some form of 'complementarity' among species ${ }^{47,48}$. Research and syntheses over the past 10 years have made it clear that both the identity and the diversity of organisms jointly control the functioning of ecosystems. Quantification of the variance explained by species identity versus diversity in $>200$ experiments found that, on average across many ecosystems, each contributes roughly $50 \%$ to the net biodiversity effect ${ }^{12}$. Complementarity may represent niche partitioning or positive species interactions ${ }^{48}$, but the extent to which these mechanisms broadly contribute to ecosystem functioning has yet to be confirmed ${ }^{12,49}$.

Loss of diversity across trophic levels has the potential to influence ecosystem functions even more strongly than diversity loss within trophic levels

Much work has shown that food web interactions are key mediators of ecosystem functioning, and that loss of higher consumers can cascade through a food web to influence plant biomass ${ }^{50,51}$. Loss of one or a few top predator species can reduce plant biomass by at least as much ${ }^{52}$ as does the transformation of a diverse plant assemblage into a species monoculture ${ }^{12}$. Loss of consumers can also alter vegetation structure, fire frequency, and even disease epidemics in a range of ecosystems ${ }^{51}$.

40 Functional traits of organisms have large impacts on the magnitude of ecosystem functions, which give rise to a wide range of plausible impacts of extinction on ecosystem function The extent to which ecological functions change following extinction depends greatly on which biological traits are extirpated ${ }^{23,53}$. Depending on the traits lost, scenarios of change vary from large reductions in ecological processes (e.g., if the surviving life form is highly unproductive) to the opposite where the efficiency, productivity, and stability of an ecosystem increase. To illustrate this latter possibility, a summary of BEF experiments showed that $65 \%$ of 1,019 experimental plots containing plant polycultures produced less biomass than that achieved by their most productive species grown 
alone $^{27}$. This result has been questioned on statistical grounds ${ }^{54}$, and because the short duration of experiments may limit the opportunity for diverse polycultures to out-perform productive species ${ }^{27}$. Even so, the key point is that, while diversity clearly impacts ecosystem functions when averaged across all genes, species, and traits, considerable variation surrounds this mean effect, stemming from differences in the identity of the organisms and their functional traits (Fig. 1). To accurately predict the consequences of any particular scenario of extinction, we must know which life forms have greatest extinction risk, and how the traits of those organisms influence function ${ }^{55}$. Quantifying functional trait diversity and linking this to both extinction risk and ecosystem processes is a rapidly expanding area of research ${ }^{53,55}$.

\section{Four emerging trends}

In addition to the consensus statements above, data published in the past few years have revealed four emerging trends that are changing the way we view the functional consequences of biodiversity loss.

\section{Impacts of diversity loss on ecological processes might be sufficiently large to rival the impacts of many other global drivers of environmental change}

While biodiversity has a significant impact on most ecosystem functions, there have been questions about whether these effects are large enough to rank among the major drivers of global change. Tilman et al. ${ }^{56}$ compared 12 long-term experiments performed at one research site, and Hooper et al. ${ }^{57}$ used a suite of meta-analyses from published data to show the impacts of species loss on primary productivity are of comparable magnitude to the impacts of drought, ultra-violet radiation, climate warming, ozone, acidification, elevated $\mathrm{CO}_{2}$, herbivory, fire, and certain forms of nutrient pollution. Because the BEF relationship is non-linear (see above), the exact ranking of diversity relative to other drivers will depend on the magnitude of biodiversity loss, as well as magnitudes of other environmental changes.

Nevertheless, these two studies suggest that diversity loss may have as quantitatively significant an impact on ecosystem functions as other global change stressors (e.g., climate change) that have already received substantial policy attention ${ }^{58}$.

\section{Diversity effects grow stronger with time, and may increase at larger spatial scales}

Diversity effects in small-scale, short-term experiments may underestimate the impacts of diversity loss on the functioning of more natural ecosystems ${ }^{45}$. At larger spatial scales and with greater temporal fluctuations, more environmental heterogeneity may increase opportunities for species to exploit more niches. Consistent with this argument, a growing body of research now shows the net effects of biodiversity on ecosystem functions grow stronger as experiments run longer ${ }^{27,46,59}$. Limited data also support the notion that diversity effects grow stronger at larger spatial scales ${ }^{12,60,61}$ and with greater resource heterogeneity ${ }^{62-64}$. Thus, BEF research to date may have under-estimated the minimum levels of biodiversity required for ecosystem processes.

\section{Maintaining multiple ecosystem processes at multiple places and times requires higher levels} of biodiversity than does a single process at a single place and time

Most BEF research has focused on one diversity-function relationship at a time. An emerging body of work suggests the number of species needed to sustain any single process is lower than the number of species needed to sustain multiple processes simultaneously ${ }^{21,65-67}$. Moreover, organisms that control ecological processes at any single location, or in any particular year, often differ from those that control processes in other locations or years ${ }^{67}$. As such, more biodiversity is required to maintain the 'multifunctionality' of ecosystems at multiple places and times. 
The ecological consequences of biodiversity loss can be predicted from evolutionary history $\mathrm{BEF}$ research has been dominated by studies that have used species richness as their primary measure of biodiversity. But species represent 'packages' for all the genetic and trait variation that influences the efficiency and metabolism of an organism, and these differences are shaped by patterns of common ancestry $^{68}$. Recent meta-analyses suggest that phylogenetic distances among species (i.e., a measure of genetic divergence) may explain more variation in biomass production than taxonomic diversity ${ }^{34,35}$. This suggests that evolutionary processes that generate trait variation among organisms are, in part, responsible for the ecosystem consequences of biodiversity loss.

\section{Years of Research on Biodiversity \& Ecosystem Services (BES)}

Over the last 20 years, researchers have developed a rigorous understanding of the services that natural and modified ecosystems provide to society ${ }^{16}$. We have learned that (a) optimizing ecosystems for certain provisioning services, especially food, fibre, and biofuel production, has greatly simplified their structure, composition, and functioning across scales, (b) simplification has enhanced certain provisioning services, but reduced others, particularly regulating services, and (c) simplification has led to major losses of biodiversity ${ }^{16}$. But critical questions remain about whether biodiversity loss per se is the cause of impaired ecosystem services in simplified landscapes.

The BES field has resulted in fewer syntheses than has the BEF field, in part because many services cannot be measured directly or manipulated experimentally. We have, therefore, summarized the balance of evidence with our own literature review (Box 2). We began by collating lists of ecosystem services that have been used in recent summaries ${ }^{15,24,33,69}$. We did not include cultural services in our review, which would describe peoples' non-consumptive uses of biodiversity such as recreation, tourism, education, science and cultural identity. Whether people are motivated by an interest in particular species (e.g., totemic or charismatic megafauna) or particular landscapes (e.g., wilderness areas or national parks), their demand for cultural services implies a demand for the biodiversity and ecosystem functions required to support the species or communities of interest. Even so, cultural services have rarely been investigated with respect to diversity per se. Here we focused our efforts on the provisioning and regulating services of ecosystems (Box 1), as these are the services that biodiversity studies have most often measured, and that are most frequently related to ecosystem functions.

We began our review by identifying data syntheses that have used either 'vote-counting' (in which the authors tallied the number of studies showing positive, negative, or non-significant relationships) or formal statistical meta-analyses (in which authors analyzed previously published data to measure standardized correlation coefficients, regression slopes or effect sizes) to quantify relationships between biodiversity and each ecosystem service. For any service for which a data synthesis was not found, we performed our own summary of peer-reviewed articles using search terms in Table S1. Papers were sorted by relevance to maximize the match to search terms, after which, we reviewed the top 100 papers for each ecosystem service (leading to a review of $>1,700$ titles and abstracts). For papers with data, we categorized the diversity-service relationship as positive, negative, or non-significant according to the authors' own statistical tests.

Detailed results of our data synthesis are summarized in Table S2, and the most salient points are given in Table 1. We believe the following statements are supported by this peer-reviewed literature:

\section{Balance of evidence}


There is now sufficient evidence that biodiversity per se either directly influences (experimental evidence), or is strongly correlated with (observational evidence) certain provisioning and regulating services

The green cells in Table 1 shows the ecosystem services for which there is sufficient evidence to conclude that biodiversity impacts the service as predicted. For provisioning services, data show that (a) intraspecific genetic diversity increases the yield of commercial crops, (b) tree species diversity enhances production of wood in plantations, (c) plant species diversity in grasslands enhances the production of fodder, and (d) increasing diversity of fish is associated with greater stability of fisheries yields. For regulating services, (e) increasing plant biodiversity increases resistance to invasion by exotic plants, (f) plant pathogens, such as fungal and viral infections, are less prevalent in more diverse plant communities, (g) plant species diversity increases aboveground carbon sequestration through enhanced biomass production (but see the next point concerning long-term C-storage), and (h) nutrient mineralization and soil organic matter increase with plant richness.

Most of these services are ones that can be directly linked to the ecosystem functions measured in BEF experiments. For example, experiments that test the effects of plant species richness on aboveground biomass production are also those that provide direct evidence for effects of diversity on aboveground carbon sequestration and on fodder production. For services less tightly linked to ecosystem functions (e.g., services associated with specific populations rather than ecosystem-level properties), we often lack rigorous verification of the diversity-service relationship.

\section{For many of the ecosystem services reviewed, the evidence for effects of biodiversity is mixed, and the contribution of biodiversity per se to the service is less well-defined}

The yellow cells in Table 1 show ecosystem services for which the available evidence has revealed mixed effects of biodiversity on the service. For example, in one data synthesis, $39 \%$ of experiments in crop production systems reported that plant species diversity led to greater yield of the desired crop species, while $61 \%$ reported reduced yield ${ }^{70}$. Impacts of biodiversity on long-term carbon storage were similarly mixed, where carbon storage refers to carbon stocks that remained in the system (in plants or soils) for $\geq 10$-years. Comparably few studies have examined storage rather than sequestration. Evidence on the effect of plant diversity on pest abundance is also mixed, with four available data syntheses showing different results. Evidence for an effect of animal diversity on the prevalence of animal disease is mixed, despite recent claims that biodiversity generally suppresses disease ${ }^{71}$. Important opportunities exist for new research to assess the factors that control variation in the response of these services to changes in biodiversity.

\section{For many services, there are insufficient data to evaluate the relationship between biodiversity and the service}

There were three ecosystem services for which we found no data, about one-third had $<5$ published relationships, and half had fewer than ten (see Table S2, white cells). This included some noteworthy examples, such as the effect of fish diversity on fisheries yield (as opposed to stability), and the effect of biodiversity on flood regulation. Surprisingly, each of these services has been cited in the literature as being a direct product of biodiversity ${ }^{16,26}$. Some of this discrepancy may be attributable to different uses of the term biodiversity (Box 1). For example, the Millennium Ecosystem Assessment reported that biodiversity enhances flood protection ${ }^{16}$, but examples were based on destruction of entire ecosystems (forests, mangroves, or wetlands) leading to increased flood risk. We did not consider complete habitat conversion in our analyses (see Box 2 for examples). 
In addition, claims about biodiversity based on ancillary evidence are not reflected in our analyses. For example, we found little direct evidence that genetic diversity enhances the temporal stability of crop yield (as opposed to total yield); yet, most farmers and crop breeders recognize that genetic diversity provides the raw material for selection of desirable traits, and can facilitate rotations that minimize crop damage caused by pests, disease, and the vagaries of weather ${ }^{72}$. While in some instances the ancillary evidence provides rather convincing evidence for a role of biodiversity in providing the ecosystem service, other cases are less convincing. This emphasizes the need for stronger and more explicit evidence to back up claims for biodiversity effects on ecosystem services.

\section{For a small number of ecosystem services, current evidence for the impact of biodiversity runs counter to expectations}

The red cells in Table 1 illustrate cases where the balance of evidence currently runs counter to claims about how biodiversity should affect the ecosystem service. For example, it has been argued that biodiversity could enhance the purity of water by removing nutrient and other chemical pollutants, or by reducing the loads of harmful pests (e.g., fecal coliform bacteria, fungal pathogens) ${ }^{16}$. There are examples where genetic or species diversity of algae enhances removal of nutrient pollutants from freshwater ${ }^{12}$, or where diversity of filter-feeding organisms reduces water-borne pathogens ${ }^{73}$. But there are even more examples that show no relationship between biodiversity and water quality.

Finally, there are instances where increased biodiversity may be deleterious. For example, while diverse assemblages of natural enemies (predators, parasitoids, and pathogens) are frequently more effective in reducing the density of herbivorous pests ${ }^{74}$, diverse natural enemy communities sometimes inhibit biocontrol ${ }^{75}$, often because enemies attack each other through intra-guild predation ${ }^{76}$. Another example relates to human health, where more diverse pathogen populations are likely to create higher risks of infectious disease, and strains of bacteria and viruses that evolve drug resistance pose health and economic burdens to people ${ }^{77}$. Such examples caution against making broad-sweeping statements that biodiversity always brings benefits to society.

\section{Outlook and Directions}

If we are to effectively manage and mitigate for the consequences of diversity loss, we need to build on the foundations laid by BEF/BES research to expand its realism, relevance, and predictive ability. At the same time, we need feedback from policy and management arenas to forge new avenues of research that will make the science even more useful. Here we consider how the next generation of biodiversity science can reduce our uncertainties and better serve policy and management initiatives for the global environment.

\section{Integrating BEF and BES}

The fields of BEF and BES have close intellectual ties, but important distinctions are evident. We see at least two avenues that could facilitate better integration. First, an important frontier involves detailing the mechanistic links between ecosystem functions and services (Box 1). The BEF field has routinely measured functions without extending those to known services, whereas the BES field has routinely described services without understanding their underlying ecological functions. A challenge to linking these two perspectives is that services are often regulated by multiple functions, which do not necessarily respond to changes in biodiversity in the same way. For example, if we want to know how biodiversity influences the ability of ecosystems to remove $\mathrm{CO}_{2}$ from the atmosphere and store carbon over long time-frames, then we need to consider the net influence of biodiversity on photosynthesis (exchange of $\mathrm{CO}_{2}$ for $\mathrm{O}_{2}$ ), carbon sequestration (accumulation of carbon in live plant tissue), herbivory 
(plant carbon eaten by animals), and decomposition (carbon returned to atmosphere as plants die and decompose). Researchers in the BEF and BES fields will need to work more closely to quantify the networks of mechanistic links between ecosystem functions and services.

Second, the fields of BEF and BES could better exploit their complementary approaches to research. Research on BEF has focused mostly on smaller spatial scales conducive to controlled experiments, which has made it difficult to scale results to real ecosystems at larger scales where services are delivered. Studies on BES have relied heavily on observational data, and often failed to separate general biotic effects on ecosystem services (e.g., biomass, habitats or entire groups of organisms) from effects of biodiversity per se (i.e., variation in life forms). To better merge these two programs, BEF and BES will need to expand their scopes of research and develop theoretical approaches that can link the smallscale, mechanistic focus of BEF research to large-scale patterns that are the focus of BES. We discuss each of these in turn.

\section{Expanding our Scope}

The need to explore more realistic scenarios of diversity change that reflect how human activities are altering biodiversity is now urgent. Organisms are not lost from ecosystems at random, and traits that predispose species to extinction are often those that drive ecosystem processes ${ }^{55,78}$. To date this issue has mostly been explored through simulations ${ }^{79,80}$, but food web theory ${ }^{81}$ based on using environmental stressors to cause nonrandom extinctions may provide a basis for a new generation of BEF experiments. Furthermore, invasions and range expansions driven by anthropogenic change are homogenizing Earth's biota and, in several cases, increasing local taxonomic diversity ${ }^{82}$. Predicting the ecosystem consequences of simultaneous gains (invasion) and losses (extinction) requires that we first understand which biological traits predispose life forms to higher probabilities of extirpation or establishment (response traits), and detail how response traits covary with traits that drive ecosystem functioning (effect traits) ${ }^{55}$. For example, at local scales invasive plants often have functional traits that are associated with more rapid resource acquisition and growth than those of coexisting native species ${ }^{83}$, although global meta-analyses suggest only modest differences between native and introduced plants in their effects on ecosystem processes ${ }^{84}$. Statistical models ${ }^{85}$ have been developed that allow integration of invasion and extinction into a trait framework, and these models should now be extended to predict changes in ecosystem services.

Another challenge is to better incorporate the real complexity of food-webs into BEF and BES research $^{30,52}$. Most research to date has focused on simplified 'model' communities. Yet, in nature, food webs are complex networks with dozens to thousands of species, have reticulate webs of indirect and non-linear interactions, and contain mismatches in the spatial and temporal dynamics of interacting organisms. This complexity can appear to preclude predictability. But recent theory ${ }^{86,87}$ and experiments ${ }^{88,89}$ suggest that food-web structure, interactions, and stability can be predicted by a small subset of traits such as organismal body size, the degree of dietary generalism ${ }^{88}$ and trophic level ${ }^{89}$. Simple trait-based approaches hold promise for simplifying the inherent complexity of natural foodwebs into a few key axes that strongly control ecosystem functions and services. We need to better identify these traits and food-web structures, and need better models to explain why certain food-web properties control ecosystem functions and services.

\section{Improving Predictions}

Increasing the complexity and realism of experiments, however, will not be enough to move biodiversity research towards better forecasting. We also need sets of models and statistical tools that help us move 
from experiments that detail local biological processes to landscape-scale patterns where management and policy take place (Fig. 2). One fruitful approach may be to use data from BEF experiments to parameterize local models of species interactions that predict how biodiversity impacts ecosystem processes based on functional traits. These local models could then be embedded into spatially explicit meta-community and ecosystem models that incorporate habitat heterogeneity, dispersal, and abiotic drivers to predict relationships between biodiversity and ecosystem services at the landscape level ${ }^{18}$. Statistical tools like Structural Equation Modeling (SEM) might then be used to assess whether predictions of these landscape models agree with observations from natural systems, and to disentangle effects of biodiversity from other covarying environmental factors ${ }^{20}$.

Ideally, predictions arising from landscape-level models would be 'ground-truthed' by assessing their ability to predict the outcome of real restoration projects, or other management scenarios where policy actions are being taken to protect ecosystem services ${ }^{90}$. For example, given land-use pressure and climate change, freshwater supply is an ecosystem service in high demand, and water funds are becoming a common finance mechanism through which downstream water consumers pay for upstream changes in land use to achieve objectives like maintenance of water quality (nutrient, sediment, and bacterial loads) ${ }^{91}$. Major initiatives are underway to standardize the design, implementation, and monitoring of water funds, including a pilot program supported by the World Bank, the Inter-American Development Bank, FEMSA, and The Nature Conservancy that spans 40 Latin American cities.

Initiatives like these represent opportunities to assess and refine our ability to predict biodiversityecosystem service relationships on realistic scales in situations where stake-holders are expecting positive returns. For example, BEF and BES researchers have amassed substantial experimental evidence showing that species diversity of plants and algae increase uptake of nutrient pollutants from soil and water $12,24,25,33,63$. We have statistical models that quantify the functional form of these effects $^{12,31}$, and extensive data on the functional traits that influence such processes in different habitats $53,63,92$. One approach could involve developing spatially-explicit predictions of how biodiversity influences water quality in a modeled watershed where local nutrient assimilation and retention are a function of the number and types of functional traits that locally co-occur (i.e., traits of plants in a riparian zone, or of algae in a stream reach). One could then integrate this spatially explicit, biologically realistic model into a decision support tool (e.g., InVEST - Integrated Valuation of Ecosystem Services and Tradeoffs $)^{93}$ to simulate changes in ecosystem services at landscape scales where decision makers can assess tradeoffs associated with alternative land-use choices (Fig. 2). Choices made by decision makers in real projects could, in turn, serve as 'natural experiments' that provide biologists an opportunity to test their predictions against outcomes.

\section{Valuing biodiversity}

Economists have developed a wide array of tools to estimate the value of natural and managed ecosystems and the market and non-marketed services they provide ${ }^{94}$. While there are good estimates of society's willingness to pay for a number of non-marketed ecosystem services, we still know little about the marginal value of biodiversity (i.e., value associated with changes in the variation of genes, species, and functional traits) in the production of those services. The economic value of biodiversity loss derives from the value of the affected services. Estimating this value requires calibration of ecosystem service 'production' functions that link biodiversity, ecosystem processes and ecosystem services. The derivative of such functions with respect to biodiversity defines the marginal physical product of biodiversity (e.g., carbon sequestration or water purification), and when multiplied by the value of the service, yields the marginal value of biodiversity change. 
Researchers in the BEF and BES fields need to work more closely to estimate the marginal value of biodiversity for ecosystem services. In doing so, at least three challenges require attention. First, ecosystems deliver multiple services, and many involve tradeoffs in that increasing the supply of one reduces the supply of another. For example, carbon sequestration through afforestation or forest protection may enhance timber production but reduce water supplies ${ }^{95}$. The value of biodiversity change to society depends on the net marginal effect of the change on all ecosystem services ${ }^{96}$. Future work needs to quantify the marginal benefits of biodiversity (in terms of services gained) relative to marginal costs (in terms of services lost).

Second, many trade-offs among services occur at very different spatial and temporal scales. The gains from simplifying ecosystems are often local and short term, while the costs are transmitted to people in other locations, or to future generations. For society to make informed choices about land uses that have mixed effects, the science linking biodiversity to ecosystem functioning and services must be extended to explore trade-offs between services at multiple temporal and spatial scales so that information can be incorporated into models of optimal land use.

Lastly, there is increasing interest in developing incentives to encourage land-holders to take full account of the ecosystem services that are affected by their actions. The concept of 'payments for ecosystem services' has emerged as one tool for bringing market value to ecosystems. Our review has emphasized that many ecosystem services ultimately depend on the variety of life forms that comprise an ecosystem, and that control the ecological processes that underlie all services. Therefore, successful plans to use payments for ecosystem services will need to be founded on a solid understanding of the linkages among biodiversity, ecosystem functioning and the production of ecosystem services ${ }^{97}$. This will require that such plans explicitly manage for biodiversity change.

\section{Responding to the call of policy initiatives}

The significance of biodiversity for human wellbeing was recognized 20 years ago with the formation of the Convention on Biological Diversity - an intergovernmental agreement among 193 countries to support the conservation of biological diversity, the sustainable use of its components, and the fair and equitable sharing of benefits. Despite this agreement, evidence gathered in 2010 indicated that biodiversity loss at the global scale was continuing, often at increasing rates ${ }^{98}$. This observation stimulated a set of new targets for 2020 (the Aichi targets) and, in parallel, governments have been negotiating the establishment of a new assessment body, the Intergovernmental Science-Policy Platform on Biodiversity and Ecosystem Services (IPBES). The IPBES will be charged with conducting regional, global and thematic assessments of biodiversity and ecosystem services, and will depend on the international scientific community to assess trends and evaluate risks associated with alternative patterns of development and changes in land use ${ }^{99}$.

Significant gaps in both the science and policy need attention if the Aichi targets are to be met, and if future ecosystems are to provide the range of services required to support more people sustainably ${ }^{99}$. We have reported the scientific consensus that has emerged over 20 years of biodiversity research, to help orient the next generation of research on the links between biodiversity and the benefits ecosystems provide to humanity. One of the greatest challenges now is to use what we have learned to develop predictive models that are founded on empirically quantified ecological mechanisms, that forecast changes in ecosystem services at scales that are policy-relevant, and that link to social, economic and political systems. Without an understanding of the fundamental ecological processes that link biodiversity, ecosystem functions and services, attempts to forecast the societal consequences of 
diversity loss, and to meet policy objectives, are likely to fail ${ }^{100}$. But with that fundamental

understanding in hand, we may yet bring the modern era of biodiversity loss to a safe end for humanity.

\section{References}

1 Jones, C. G., Lawton, J. H. \& Shachak, M. Organisms as ecosystem engineers. Oikos 69, 373-386, (1994).

2 Sterner, R. W. \& Elser, J. J. Ecological stoichiometry: The biology of elements from molecules to the biosphere. (Princeton University Press, 2002).

3 Power, M. E. et al. Challenges in the quest for keystones. BioScience 46, 609-620, (1996). Schulze, E. D. \& Mooney, H. A. Biodiversity and ecosystem function. (Springer-Verlag, 1993). This influential book established many of the orginal hypotheses and ideas that laid the foundation for two decades of empircal work in BEF.

5 Heywood, V. H., Watson, R. T. \& Programme, U. N. E. Global biodiversity assessment. (Cambridge University Press, 1995).

6 Loreau, M. et al. DIVERSITAS Science Plan. (2002).

7 Tilman, D. \& Downing, J. A. Biodiversity and stability in grasslands. Nature 367, 363-365, (1994). This study, along with Naeem et al. 1994 (ref 8), started a whole generation of research that examined how biodiversity influences the functioning of ecosystems.

8 Naeem, S., Thompson, L. J., Lawler, S. P., Lawton, J. H. \& Woodfin, R. M. Declining biodiversity can alter the performance of ecosystems. Nature 368, 734-737, (1994).

9 Tilman, D., Wedin, D. \& Knops, J. Productivity and sustainability influenced by biodiversity in grassland ecosystems. Nature 379, 718-720, (1996).

10 Hector, A. et al. Plant diversity and productivity experiments in European grasslands. Science 286, 1123-1127, (1999).

11 Loreau, M., Naeem, S. \& Inchausti, P. Biodiversity and Ecosystem Functioning: Synthesis and Perspectives. (Oxford University Press, 2002). This book, which followed a 2000 conference in Paris, summarized the first decade of BEF research.

12 Cardinale, B. J. et al. The functional role of producer diversity in ecosystems. American Journal of Botany 98, 572-592, (2011).

Daily, G. C. Nature's Services: Societal Dependence on Natural Ecosystems. (Island Press, 1997).

This book cemented the notion that natural habitats provide essential goods services to society, and it helped make 'ecosystem services' a mainstream term.

14 Perrings, C., Folke, C. \& Maler, K. G. The ecology and economics of biodiversity loss - The research agenda. Ambio 21, 201-211, (1992).

15 Mace, G. M., Norris, K. \& Fitter, A. H. Biodiversity and ecosystem services: a multilayered relationship. Trends in ecology \& evolution 27, 19-26, (2012).

16 MEA. The Millennium Ecosystem Assessment, Ecosystems and human well-being: Biodiversity synthesis. 86 (World Resources Institute, Washington D.C., 2005).

17 Kinzig, A. P., Pacala, S. W. \& Tilman, D. The Functional Consequences of Biodiversity: Empirical Progress and Theoretical Extensions. (Princeton University Press, 2002).

18 Loreau, M. From Populations to Ecosystems: Theoretical Foundations for a New Ecological Synthesis. (Princeton University Press, 2010).

19 Tilman, D., Lehman, D. \& Thompson, K. Plant diversity and ecosystem productivity: Theoretical considerations. Proceedings of the National Academy of Sciences 94, 1857-1861, (1997).

20 Paquette, A. \& Messier, C. The effect of biodiversity on tree productivity: from temperate to boreal forests. Glob. Ecol. Biogeogr. 20, 170-180, (2011). This paper, along with Maestre et al. 2012 (ref 21), exemplify how to quantify biodiversity effects on ecosystem functions at large scales in real ecosystems. 
21 Maestre, F. T. et al. Plant species richness and ecosystem multifunctionality in global drylands. Science 335, 214-218, (2012).

22 Mora, C. et al. Global human footprint on the linkage between biodiversity and ecosystem functioning in reef fishes. PLOS. Biol. 9, (2011).

23 Hooper, D. U. et al. Effects of biodiversity on ecosystem functioning: A consensus of current knowledge. Ecological Monographs 75, 3-35, (2005). This paper was the last published scientific consensus statement on how biodiversity influences ecosystem functions and services.

24 Balvanera, P. et al. Quantifying the evidence for biodiversity effects on ecosystem functioning and services. Ecology Letters 9, 1146-1156, (2006). This paper, along with Cardinale et al. 2006 (ref 25), were the first to synthesize BEF research via statistical meta-analyses.

25 Cardinale, B. J. et al. Effects of biodiversity on the functioning of trophic groups and ecosystems. Nature 443, 989-992, (2006).

26 Worm, B. et al. Impacts of biodiversity loss on ocean ecosystem services. Science 314, 787-790, (2006).

27 Cardinale, B. J. et al. Impacts of plant diversity on biomass production increase through time due to complementary resource use: A meta-analysis. Proceedings of the National Academy of Sciences 104, 18123-18128, (2007).

28 Stachowicz, J., Bruno, J. F. \& Duffy, J. E. Understanding the effects of marine biodiversity on communities and ecosystems. Annual Review of Ecology, Evolution and Systematics 38, 739-766 (2007).

29 Bruno, J. F. \& Cardinale, B. J. Cascading effects of predator richness. Frontiers in Ecology and the Environment 6, 539-546, (2008).

30 Cardinale, B. J. et al. in Biodiversity and Human Impacts (eds S. Naeem et al.) 105-120 (Oxford University Press, 2009).

31 Schmid, B. et al. in Biodiversity and Human Impacts (eds S. Naeem et al.) 14-29 (Oxford University Press, 2009).

32 Srivastava, D. S. et al. Diversity has stronger top-down than bottom-up effects on decomposition. Ecology 90, 1073-1083, (2009).

33 Quijas, S., Schmid, B. \& Balvanera, P. Plant diversity enhances provision of ecosystem services: A new synthesis. Basic Appl. Ecol. 11, 582-593, (2010).

34 Cadotte, M. W., Cardinale, B. J. \& Oakley, T. H. Evolutionary history and the effect of biodiversity on plant productivity. Proceedings of the National Academy of Sciences 105, 17012-17017, (2008).

35 Flynn, D. F. B., Mirotchnick, N., Jain, M., Palmer, M. I. \& Naeem, S. Functional and phylogenetic diversity as predictors of biodiversity-ecosystem-function relationships. Ecology 92, 1573-1581, (2011).

Wardle, D. A., Bonner, K. I. \& Nicholson, K. S. Biodiversity and plant litter: Experimental evidence which does not support the view that enhanced species richness improves ecosystem function. Oikos 79, 247-258, (1997). of ecological systems. Ecology Letters 4, 72-85, (2001).

39 Jiang, L. \& Pu, Z. C. Different effects of species diversity on temporal stability in single-trophic and multitrophic communities. American Naturalist 174, 651-659, (2009). Hector, A. et al. General stabilizing effects of plant diversity on grassland productivity through population asynchrony and overyielding. Ecology 91, 2213-2220, (2010). interpretation of diversity-stability relations. Oikos 120, 399-408, (2011). 

University Press, 2009).

43 Doak, D. F. et al. The statistical inevitability of stability-diversity relationships in community ecology. American Naturalist 151, 264-276, (1998).

44 Gonzalez, A. \& Loreau, M. The causes and consequences of compensatory dynamics in ecological communities. Annual Review of Ecology Evolution and Systematics 40, 393-414, (2009).

45 Duffy, J. E. Why biodiversity is important to the functioning of real-world ecosystems. Frontiers in Ecology and the Environment 7, 437-444, (2009).

Tilman, D. et al. Diversity and productivity in a long-term grassland experiment. Science 294, $843-845,(2001)$. This experiment continues to be one of the largest and longest running biodiversity studies ever run.

47 Huston, M. A. Hidden treatments in ecological experiments: Re-evaluating the ecosystem function of biodiversity. Oecologia 110, 449-460, (1997). This paper levied several criticisms against early BEF research, which forced us to reconsider conclusions with better experiments and more rigorous data analyses.

48 Loreau, M. \& Hector, A. Partitioning selection and complementarity in biodiversity experiments. Nature 412, 72-76, (2001).

49 Carroll, I. T., Cardinale, B. J. \& Nisbet, R. M. Niche and fitness differences relate the maintenance of diversity to ecosystem function. Ecology 92, 1157-1165, (2011).

50 Shurin, J. B. et al. A cross-ecosystem comparison of the strength of trophic cascades. Ecology Letters 5, 785-791, (2002).

51 Estes, J. A. et al. Trophic downgrading of planet earth. Science 333, 301-306, (2011). This paper summarizes how extinction of large carnivores impacts ecosystem processes, which emphasizes the urgent need to integrate trophic interactions into BEF and BES research.

52 Duffy, J. E. et al. The functional role of biodiversity in ecosystems: Incorporating trophic complexity Ecology Letters 10, 522-538, (2007).

53 Diaz, S. et al. Incorporating plant functional diversity effects in ecosystem service assessments. Proceedings of the National Academy of Sciences of the United States of America 104, 20684$20689,(2007)$. This paper outlined a framework for linking species functional traits to ecosystem services, which moves the field of BES research towards more predictive models. Schmid, B., Hector, A., Saha, P. \& Loreau, M. Biodiversity effects and transgressive overyielding. Journal of Plant Ecology 1, 95-102, (2008).

55 Suding, K. N. et al. Scaling environmental change through the community-level: a trait-based response-and-effect framework for plants. Glob. Change Biol. 14, 1125-1140, (2008). Tilman, D., Reich, P. \& Isbell, F. Biodiversity impacts ecosystem productivity as much as resources, disturbance or herbivory. Proceedings of the Natlonal Academy of Sciences in press.

57 Hooper, D. U. et al. Biodiversity loss ranks as a major driver of ecosystem change. Nature in press.

IPCC. (Cambridge University, 2007).

59 Stachowicz, J. J., Graham, M., Bracken, M. E. S. \& Szoboszlai, A. I. Diversity enhances cover and stability of seaweed assemblages: The role of heterogeneity and time. Ecology 89, 3008-3019, (2008).

60 Dimitrakopoulos, P. G. \& Schmid, B. Biodiversity effects increase linearly with biotope space. Ecology Letters 7, 574-583, (2004).

61 Venail, P. A., Maclean, R. C., Meynard, C. N. \& Mouquet, N. Dispersal scales up the biodiversityproductivity relationship in an experimental source-sink metacommunity. Proceedings of the Royal Society B-Biological Sciences 277, 2339-2345, (2010). 
Tylianakis, J. M. et al. Resource heterogeneity moderates the biodiversity-function relationship in real world ecosystems. PLOS. Biol. 6, 947-956, (2008).

63 Cardinale, B. J. Biodiversity improves water quality through niche partitioning. Nature 472, 8689, (2011).

64 Finke, D. L. \& Snyder, W. E. Niche partitioning increases resource exploitation by diverse communities. Science 321, 1488-1490, (2008).

65 Hector, A. \& Bagchi, R. Biodiversity and ecosystem multifunctionality. Nature 448, 188-190, (2007).

66 Zavaleta, E. S., Pasari, J. R., Hulvey, K. B. \& Tilman, G. D. Sustaining multiple ecosystem functions in grassland communities requires higher biodiversity. Proceedings of the National Academy of Sciences 107, 1443-1446, (2010).

67 Isbell, F. et al. High plant diversity is needed to maintain ecosystem services. Nature 477, 199202, (2011).

68 Mace, G. M., Gittleman, J. L. \& Purvis, A. Preserving the tree of life. Science 300, 1707-1709, (2003).

69 Diaz, S., Fargione, J., Chapin, F. S. \& Tilman, D. Biodiversity loss threatens human well-being. PLoS. Biol. 4, 1300-1305, (2006).

70 Letourneau, D. K. et al. Does plant diversity benefit agroecosystems? A synthetic review. Ecological Applications 21, 9-21, (2011).

Keesing, F. et al. Impacts of biodiversity on the emergence and transmission of infectious diseases. Nature 468, 647-652, (2010).

72 Zhang, W., Ricketts, T. H., Kremen, C., Carney, K. \& Swinton, S. M. Ecosystem services and disservices to agriculture. Ecol. Econ. 64, 253-260, (2007).

73 Latta, L. C. et al. Species and genotype diversity drive community and ecosystem properties in experimental microcosms. Evol. Ecol. 25, 1107-1125, (2011).

74 Denoth, M., Frid, L. \& Myers, J. H. Multiple agents in biological control: improving the odds? Biological Control 24, 20-30, (2002).

75 Letourneau, D. K., Jedlicka, J. A., Bothwell, S. G. \& Moreno, C. R. Effects of natural enemy biodiversity on the suppression of arthropod herbivores in terrestrial ecosystems. Annual Review of Ecology Evolution and Systematics 40, 573-592, (2009).

76 Vance-Chalcraft, H. D., Rosenheim, J. A., Vonesh, J. R., Osenberg, C. W. \& Sih, A. The influence of intraguild predation on prey suppression and prey release: A meta-analysis. Ecology 88, 26892696, (2007).

77 Taylor, L. H., Latham, S. M. \& Woolhouse, M. E. J. Risk factors for human disease emergence. Philosophical Transactions of the Royal Society of London Series B-Biological Sciences 356, 983 989, (2001).

78 Wardle, D. A., Bardgett, R. D., Callaway, R. M. \& Van der Putten, W. H. Terrestrial ecosystem responses to species gains and losses. Science 332, 1273-1277, (2011).

79 Solan, M. et al. Extinction and ecosystem function in the marine benthos. Science 306, 11771180, (2004).

80 Bunker, D. E. et al. Species loss and aboveground carbon storage in a tropical forest. Science 310, 1029-1031, (2005).

81 Ives, A. R. \& Cardinale, B. J. Food-web interactions govern the resistance of communities after non-random extinctions. Nature 429, 174-177, (2004).

82 Sax, D. F. \& Gaines, S. D. Species diversity: from global decreases to local increases. Trends in Ecology \& Evolution 18, 561-566, (2003).

83 Bardgett, R. D. \& Wardle, D. A. Aboveground-belowground linkages: biotic interactions, ecosystem processes, and global change. (Oxford University Press, 2010). 
84 Vila, M. et al. Ecological impacts of invasive alien plants: a meta-analysis of their effects on species, communities and ecosystems. Ecology Letters 14, 702-708, (2011).

85 Fox, J. W. \& Kerr, B. Analyzing the effects of species gain and loss on ecosystem function using the extended Price equation partition. Oikos 121, 290-298, (2012).

86 Loeuille, N. \& Loreau, M. Evolutionary emergence of size-structured food webs. Proceedings of the National Academy of Sciences 102, 5761-5766, (2005).

87 Berlow, E. L. et al. Simple prediction of interaction strengths in complex food webs. Proceedings of the National Academy of Sciences 106, 187-191, (2009).

88 O'Gorman, E. J., Jacob, U., Jonsson, T. \& Emmerson, M. C. Interaction strength, food web topology and the relative importance of species in food webs. Journal of Animal Ecology 79, 682-692, (2010).

89 Wood, S. A., Lilley, S. A., Schiel, D. R. \& Shurin, J. B. Organismal traits are more important than environment for species interactions in the intertidal zone. Ecology Letters 13, 1160-1171, (2010).

90 Kinzig, A. P. et al. Paying for ecosystem services-promise and peril. Science 334, 603-604, (2011).

91 Goldman, R. et al. Water funds and PES: Practice learns from theory and theory can learn from practice. Oryx in press, (2012).

92 Kattge, J. et al. TRY - a global database of plant traits. Glob. Change Biol. 17, 2905-2935, (2011).

93 Kareiva, P., Tallis, H., Ricketts, T., Daily, G. \& Polasky, S. (Oxford University Press, 2011).

Heal, G. M. et al. Valuing Ecosystem Services: Toward Better Environmental Decision Making. (The National Academies Press, 2005). This NRC report outlines how we might better integrate ecology and economics to address environmental problems that involve changes in ecosystem services.

95 Jackson, R. B. et al. Trading water for carbon with biological carbon sequestration. Science 310, 1944-1947, (2005).

96 Perrings, C. et al. Ecosystem services, targets, and indicators for the conservation and sustainable use of biodiversity. Frontiers in Ecology and the Environment 9, 512-520, (2011).

97 Kinzig, A. P. et al. Ecosystem Services: Free lunch no more response. Science 335, 656-U131, (2012).

Butchart, S. H. M. et al. Global biodiversity: Indicators of recent declines. Science 328, $1164-$ 1168, (2010).

99 Perrings, C., Duraiappah, A., Larigauderie, A. \& Mooney, H. The biodiversity and ecosystem services science-policy interface. Science 331, 1139-1140, (2011).

100 Larigauderie, A. et al. Biodiversity and ecosystem services science for a sustainable planet: The DIVERSITAS vision for 2012-20. Current Opinion in Environmental Sustainability in press, (2012).

Supplementary Information is linked to the online version of the paper at www.nature.com/nature.

Acknowledgements This work was conceived as a part of the working group, Biodiversity and the Functioning of Ecosystems: Translating Model Experiments into Functional Reality, supported by the National Center for Ecological Analysis and Synthesis, a Center funded by the National Science Foundation (NSF Grant \#EF-0553768), the University of California, Santa Barbara, and the State of California. Additional funds were provided by NFS's DIMENSIONS of Biodiversity program to BJC (DEB104612), and by the Biodiversity and Ecosystem Services Research Training Network (BESTNet) (NSF Grant \#0639252). The use of trade names is for descriptive purposes only and does not imply endorsement by the U.S. Government. 
Author information Reprints and permissions information is available at www.nature.com/reprints. The authors declare they have no competing financial interests. Correspondence and requests for materials should be addressed to bradcard@umich.edu. 


\section{BOX 1}

\section{What is this Review about?}

Here we ask how biodiversity per se - meaning, the variety of genes, species, or functional traits in an ecosystem impacts the functioning of that ecosystem and, in turn, the services the ecosystem provides to humanity (yellow arrows, figure below). This encompasses questions like ... Can a forest store more carbon if it has a greatervariety of tree species? Can a stream clean up more pollution if it has a greatervariety of microbial genotypes? Can natural enemies better control agricultural pests if they are composed of a variety of predators, parasites, and pathogens?

\section{What is Biodiversity?}

The variety of life, including variation among genes, species, and functional traits.

- Richness: number of unique life forms

- Evenness: equitability among life forms

- Heterogeneity: dis-similarity among life forms

\section{What are Ecosystem Functions?}

Ecological processes that control the fluxes of energy, nutrients, and organic matter through an environment. Examples include ...

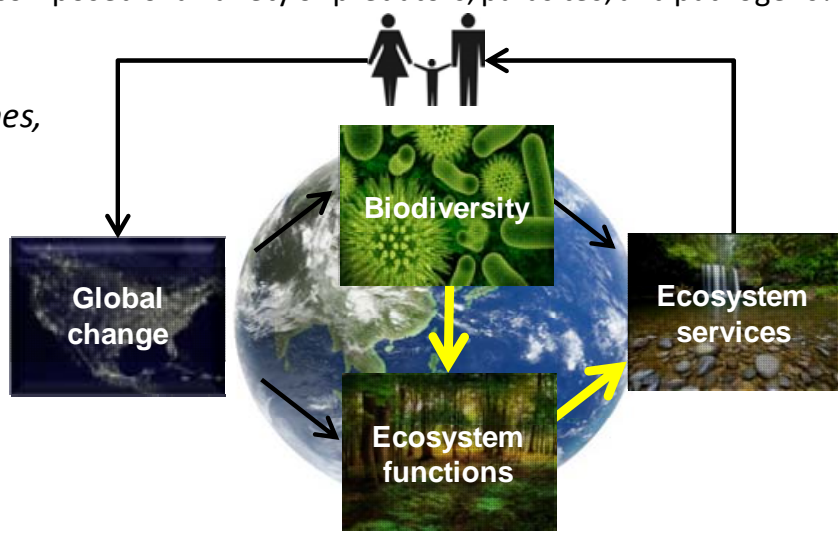

- Primary production: the process by which plants use sunlight to convert inorganic matter into new biological tissue - Nutrient cycling: the process by which biologically essential nutrients are captured, released, and then recaptured - Decomposition: the process by which organic wastes like dead plants and animals are broken-down and recycled

\section{What are Ecosystem Services?}

The suite of benefits that ecosystems provide to humanity ${ }^{\dagger}$

- Provisioning services: Production of renewable resources (e.g., food, wood, freshwater)

- Regulating services: Processes that lessen environmental change (e.g., climate regulation, pest/disease control)

${ }^{\dagger}$ We do not consider cultural services in this review (e.g., recreation, tourism, education), as few empirical studies have related these values to biodiversity per se. 


\section{BOX 2}

\section{What evidence links biodiversity to ecosystem services?}

We reviewed $>1,700$ papers to summarize the balance of evidence linking biodiversity to the goods and services provided by ecosystems. We collated lists of provisioning and regulating services that have been the focus of recent summaries (Table S1), and then searched the ISI Web of Knowledge to identify any previously published data syntheses that have summarized known relationships between biodiversity and each ecosystem service. When a data synthesis was not found, we completed our own summary of peer-reviewed articles and categorized the diversity-service relationship as positive, negative, or non-significant according to the authors' own statistical tests. Articles had to meet the following criteria for inclusion:

1. Study had to explicitly test for a relationship between biodiversity (defined in Box 1) and the focal ecosystem service using experimental (diversity manipulated) or observational (diversity not manipulated) data.

2. Study had to quantify biodiversity and the focal service directly (i.e., studies using proxies were excluded). 3. If authors of the original study identified confounding variables, data were included only if effects of those confounding variables were statistically controlled for before quantifying the diversity-service relationship. 4. Study had to compare a more diverse to less diverse ecosystem containing at least one service providing unit. Any comparison to ecosystems with no service providing unit was excluded (see examples below).

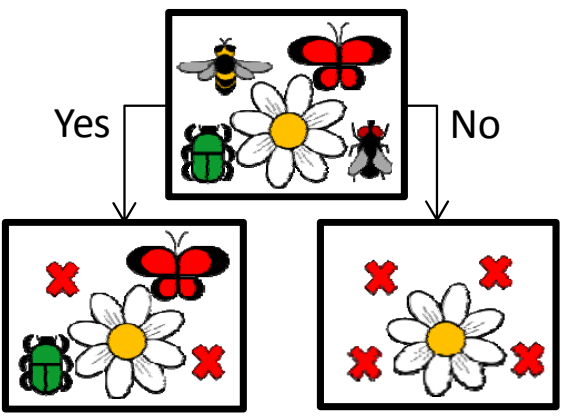

Example 1. Pollination is an ecosystem service provided by a wide variety of organisms, and is essential to the production of many of the world's food crops. We considered studies that compare services like pollination success (e.g., fruit set) in a diverse system to a less diverse system (bottom left). But we excluded studies comparing services of a diverse system to one with no service providing organisms (bottom right). While the latter can quantify the value of service providing organisms (e.g., pollinators), it says nothing about the role of biodiversity.

Example 2. Forests provide a wide array of ecosystem services such as carbon sequestration, wood production, and water purification. We considered studies that compare diverse to less diverse habitats (bottom left). But we did not consider studies that compare services in diverse habitats to those where the habitat was destroyed (e.g., clear-cut). While the latter may show the value of the habitat for ecosystem services, it cannot tell us the role of biodiversity.

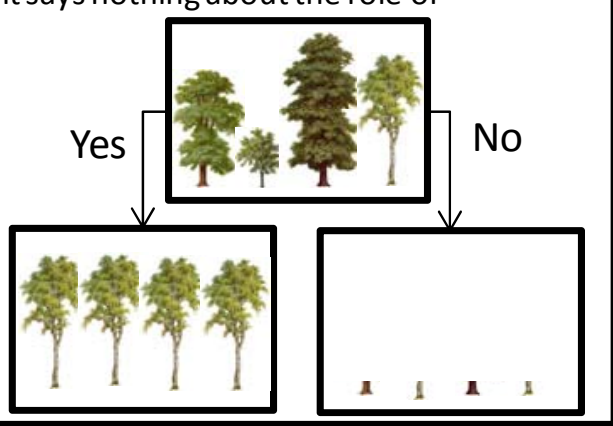


Table 1. Balance of evidence linking biodiversity to ecosystem services.

\begin{tabular}{|c|c|c|c|c|c|c|c|c|c|}
\hline \multirow{2}{*}{\multicolumn{2}{|c|}{ Category }} & \multirow{4}{*}{$\begin{array}{l}\text { Ecosystem service } \\
\text { Crop yield }\end{array}$} & \multirow{4}{*}{$\begin{array}{c}\text { SPU } \\
\mathrm{PI}\end{array}$} & \multirow{4}{*}{\begin{tabular}{|l|}
$\mathrm{DL}$ \\
$\mathrm{G}$ \\
$\mathrm{S}$ \\
\end{tabular}} & \multirow{4}{*}{$\begin{array}{c}\text { Source } \\
\text { DS } \\
\text { DS }\end{array}$} & \multirow{4}{*}{$\begin{array}{c}\begin{array}{c}\text { Study } \\
\text { type }\end{array} \\
\text { Exp } \\
\text { Exp }\end{array}$} & \multirow{4}{*}{$\begin{array}{c}\mathrm{N} \\
575 \\
100\end{array}$} & \multicolumn{2}{|c|}{ Relationship } \\
\hline & & & & & & & & Pred & Act \\
\hline \multirow{5}{*}{ 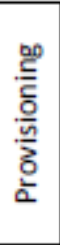 } & Crons & & & & & & & 2 & 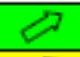 \\
\hline & Crops & & & & & & & 2 & \& \\
\hline & Fisheries & Stability of fisheries yield & $\mathrm{Fi}$ & S & PS & Obs & 8 & 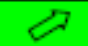 & 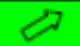 \\
\hline & Wood & Wood production & $\mathrm{Pl}$ & $\mathrm{S}$ & DS & Exp & 53 & 2 & 2 \\
\hline & Fodder & Fodder yield & $\mathrm{PI}$ & S & DS & Exp & 271 & 2 & $\nabla$ \\
\hline \multirow{17}{*}{ 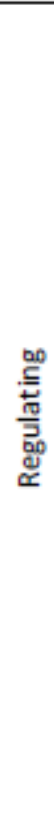 } & \multirow{10}{*}{ Biocontrol } & \multirow{4}{*}{$\begin{array}{l}\text { Control of herbivorous pests } \\
\text { (bottom-up effect of plant } \\
\text { diversity) }\end{array}$} & \multirow{4}{*}{$\mathrm{Pl}$} & \multirow{4}{*}{ S } & $\mathrm{DS}^{\circ}$ & Obs & 40 & 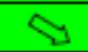 & $\mathrm{y}$ \\
\hline & & & & & $\mathrm{DS}^{\mathrm{b}}$ & Exp & 100 & & 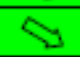 \\
\hline & & & & & DS $^{\mathrm{c}}$ & Exp & 287 & & 6 \\
\hline & & & & & $\mathrm{DS}^{d}$ & Exp & 100 & & 0 \\
\hline & & \multirow{3}{*}{$\begin{array}{l}\text { Control of herbivorous pests } \\
\text { (top-down effect of natural } \\
\text { enemy diversity) }\end{array}$} & \multirow{3}{*}{ NE } & $\mathrm{S} / \mathrm{T}$ & $\mathrm{DS}^{\mathrm{a}}$ & Obs & 18 & $S$ & 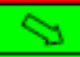 \\
\hline & & & & s & $\mathrm{DS}^{\mathrm{b}}$ & Exp/Obs & 266 & 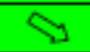 & 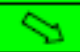 \\
\hline & & & & $\mathrm{s}$ & $\mathrm{DS}^{\mathrm{c}}$ & Exp & 38 & S & 23 \\
\hline & & Resistance to plant invasion & $\mathrm{Pl}$ & S & DS & Exp & 120 & 2 & 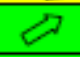 \\
\hline & & Disease prevalence (on plants) & $\mathrm{PI}$ & S & DS & Exp & 107 & $\mathrm{~S}$ & $S$ \\
\hline & & Disease prevalence (on animals) & $\mathrm{M}$ & $\mathrm{S}$ & DS & Exp/Obs & 45 & 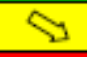 & 23 \\
\hline & \multirow{3}{*}{ Climate } & Primary production & $\mathrm{PI}$ & $\mathrm{s}$ & DS & Exp & 7 & 2 & 0 \\
\hline & & Carbon sequestration & $\mathrm{PI}$ & S & DS & Exp & 479 & 2 & $\nabla$ \\
\hline & & Carbon storage & $\mathrm{PI}$ & $\mathrm{S} / \mathrm{T}$ & PS & Obs & 33 & 2 & \$8 \\
\hline & \multirow{2}{*}{ Soil } & Soil nutrient mineralization & $\mathrm{Pl}$ & S & DS & Exp & 103 & 2 & 2 \\
\hline & & Soil organic matter & $\mathrm{PI}$ & $\mathrm{s}$ & DS & Exp & 85 & 2 & $\nabla$ \\
\hline & Water & Freshwater purification & $M$ & $\mathrm{G} / \mathrm{S}$ & PS & Exp & 8 & 27 & 0 \\
\hline & Pollination & Pollination & $\ln$ & $\mathrm{s}$ & PS & Obs & 7 & $\nabla$ & 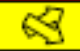 \\
\hline
\end{tabular}

For each ecosystem service we searched the ISI Web of Science for published data syntheses (DS). The super-scripts in the Source column refer to different syntheses. When a synthesis was not available, we completed our own primary search (PS, see Box 2). Detailed results are given in Table S2. Data presented here are summarized as follows: Green = Actual (Act) data relationships agree with predictions (Pred). Yellow $=$ data show mixed results. Red $=$ data conflict with predictions. $\mathrm{SPU}=$ service providing unit ( $\mathrm{Fi}=$ fish, $\mathrm{In}=$ insects, $\mathrm{M}=$ multiple, $\mathrm{NE}=$ natural enemies, including predators, parasitoids, and pathogens, $\mathrm{Pl}=$ plants). $\mathrm{DL}=$ diversity level $(\mathrm{S}=$ species, $\mathrm{G}=$ genetic, $\mathrm{T}=$ trait). Study type (Exp = experimental, Obs = observational). $\mathrm{N}=$ number of data points. Note that 13 ecosystem services are not included in this table due to lack of data ( $<5$ relationships, see Table S2). 


\section{Figure legends}

Fig 1. The form of a typical diversity-function relationship. This conceptual diagram summarizes what we know about the shape of the Biodiversity-Ecosystem Functioning (BEF) relationship based on summaries of several hundred experiments ${ }^{12,24-35}$. The red-line shows the average change across all combinations of genes, species, or traits. The grey polygon represents the $95 \%$ confidence interval, while red dots give max/min values of the most or least productive species grown alone in monoculture (note: see main text about uncertainties associated with upper bound). To improve our predictions of how diversity loss influences the goods and services of ecosystems, we must now take this experimental relationship and (1) link the ecosystem functions measured in experiments to the provisioning and regulating services of ecosystems, (2) expand the focus of research to better mimic realistic extinction scenarios and trophic structures of natural ecosystems, and (3) develop mathematical models that can scale experimental results to whole landscapes.

Fig 2. Towards a better link between BEF and BES research. One of our greatest challenges now is to take what we have learned from 20 years of research and develop predictive models that are founded on empirically quantified mechanisms, and that forecast changes in ecosystem services at scales that are policy-relevant. We outline a hypothetical approach for linking biodiversity to the maintenance of 'water quality' at landscape scales. Data from BEF experiments are used to parameterize competition or niche models that predict how biodiversity impacts nutrient assimilation and retention (step 1). Local models are then embedded in spatially explicit meta-community or ecosystem models that incorporate habitat heterogeneity, dispersal, and abiotic drivers to predict relationships between biodiversity and water quality at landscape scales (step 2 ). Predictions of the landscape model are compared to observations from natural systems to assess fit, and statistical tools are used to disentangle effects of biodiversity from other environmental factors (step 3). Once a satisfactory fit is achieved, the model is integrated into a decision support tool (e.g., InVEST - Integrated Valuation of Ecosystem Services and Tradeoffs), which is used to simulate changes in ecosystem services at landscape scales where decision makers assess alternative land-use choices (step 5). Choices made by decision makers in real projects provide new data that allow biologists to refine their models and predictions (step 6). 
Fig 1.

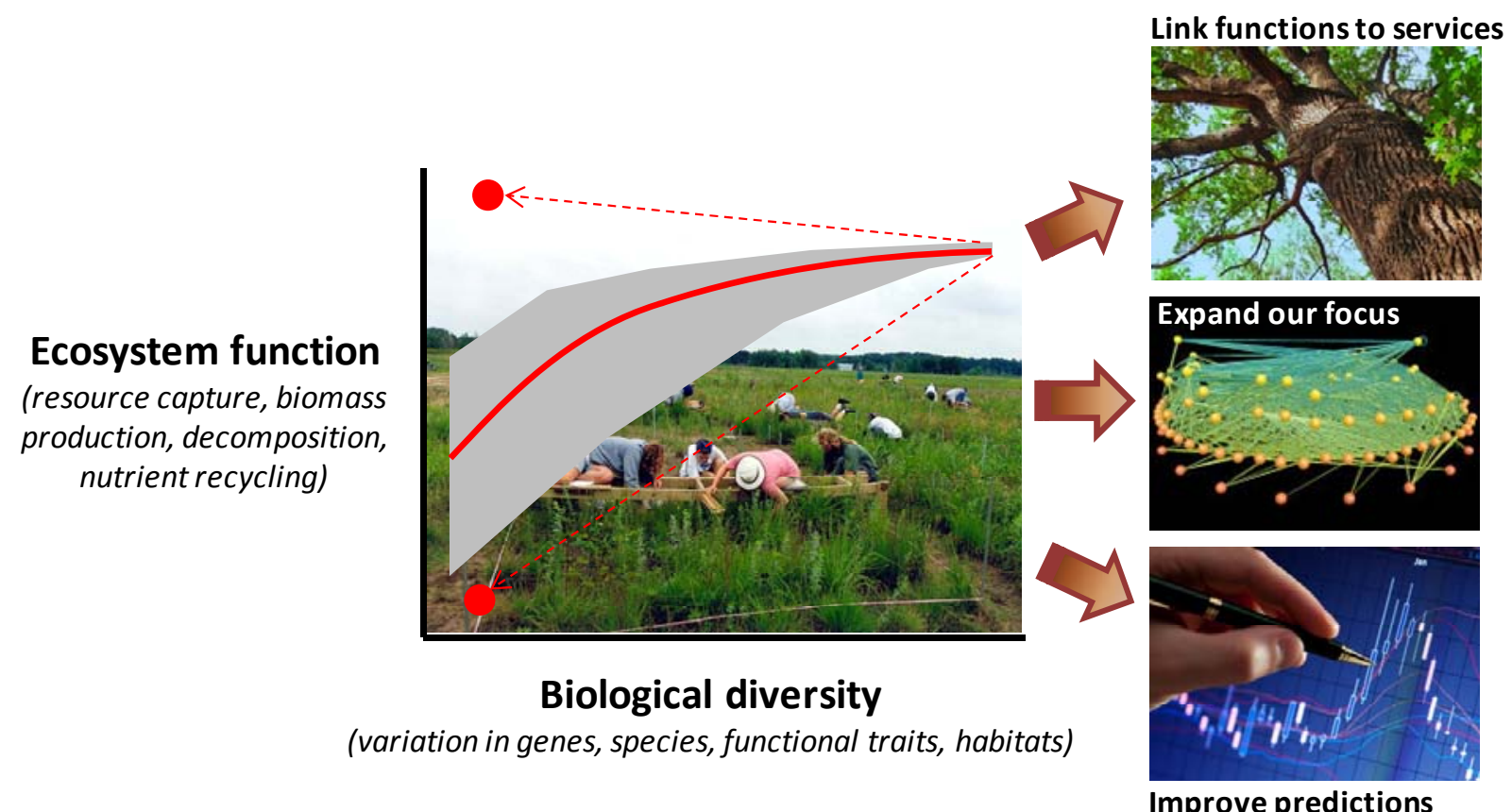


Fig 2.

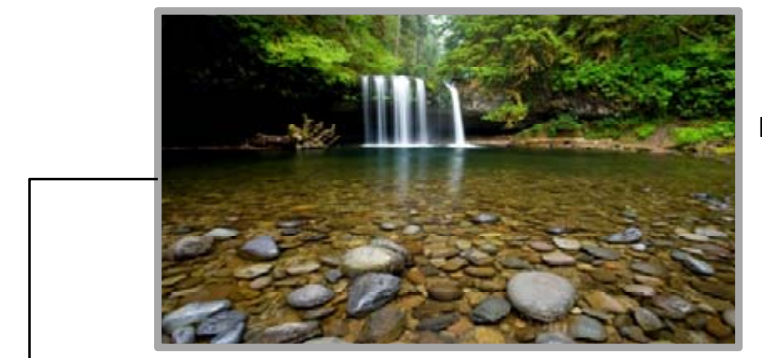

(3)

Use statistical tools to fit predicted data to observed data from real watersheds (e.g. Structural Equations Modeling).

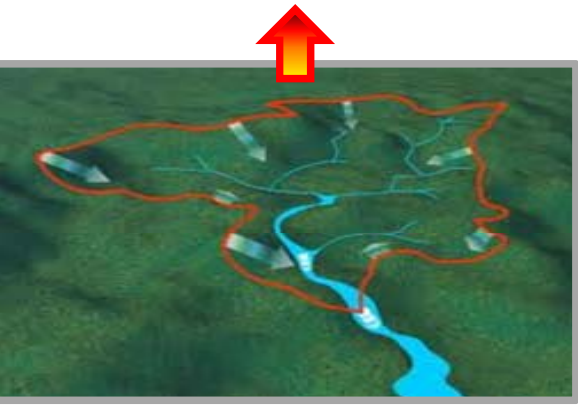

Embed local model into ecosystem model that

(2) predicts nutrient uptake as a function of diversity in simulated watersheds.

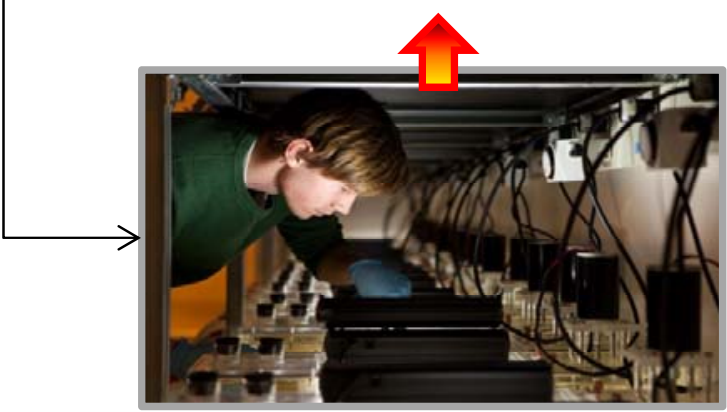

(1) Use BEF experiments to parameterize local 1 models relating nutrient uptake to diversity of producer functional traits.

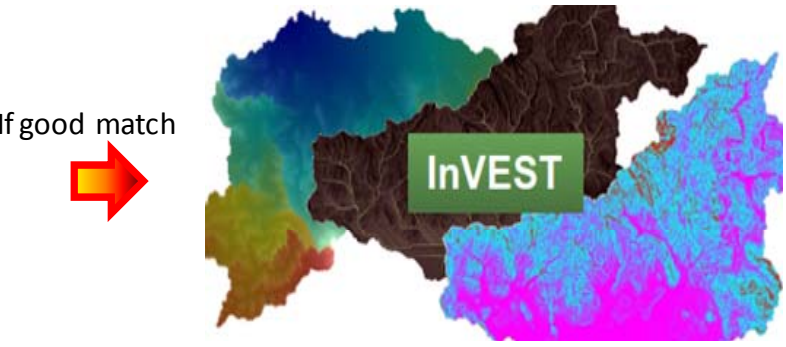

(4) Integrate spatially explicit, biologically realistic model into a decision support tool (e.g., InVEST )

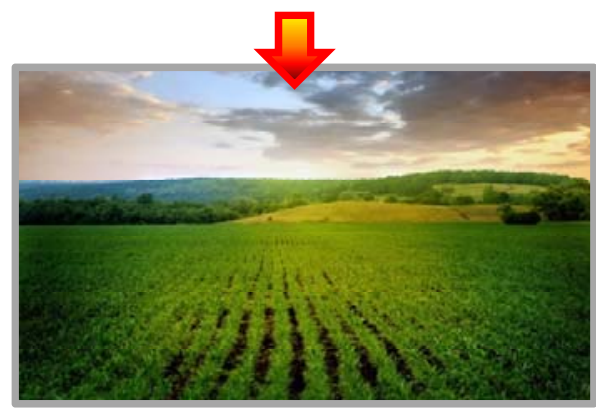

Use InVEST to assess tradeoffs associated

5 with alternative land-use choices that influence water quality.

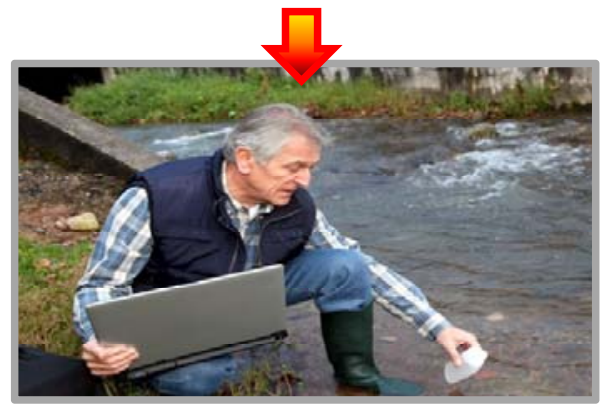

6

Use choices made by decision makers as a 'natural experiment' to better match predictions to outcomes. 